\title{
A Leitura Popular da Bíblia e SEU IMPACTO NA RENOVAÇÃo dA CATEQUESE NA AMÉRICA LATINA
}

\author{
LA LECTURE POPULAIRE DE LA BIBLE ET SON IMPACT SUR LE \\ RENOUVEAU DE LA CATÉCHÈSE EN AMÉRIQUE LATINE
}

\author{
Solange Maria do Carmo * \\ João Ferreira Júnior **
}

\begin{abstract}
RESUMO
Apropriando-se das intuições do Vaticano II, Medellín assumiu o princípio de unidade entre a história da salvação e a história humana (fé e vida), o que possibilitou um olhar diferenciado sobre as realidades de pobreza dos povos da América-Latina. A partir dos pobres, um novo modo de ler a bíblia veio à luz, a leitura popular da bíblia, e através dele um outro jeito de fazer catequese. Duas mudanças importantes foram sentidas: no campo pedagógico e no campo do conteúdo. A pedagogia do ensinamento, que considerava o catequizando como uma tábula rasa, foi substituída pela pedagogia da aprendizagem, que passou a assumir o catequizando como protagonista do ato catequético. O conteúdo dos encontros, antes focado na doutrina, cedeu lugar para a realidade histórica do catequizando. Mais que aprender conteúdos, tornou-se importante ler a vida sob a ótica da fé, assumindo seus desafios e pelejas, para transformá-la pela força do Deus libertador.
\end{abstract}

Palavras-chave: Medellín. Catequese. Bíblia.

\section{RESUMÉ}

En s'appropriant des certaines intuitions de Vatican II, Medellín a repris le principe d'unité entre l'histoire du salut et l'histoire humaine (foi et vie), avec un regard différencié sur les réalités de pauvreté des peuples latino-américains. Une nouvelle façon de lire la Bible à partir des pauvres a emergée, une lecture populaire de la Bible et, à travers elle, une nouvelle manière de proposer le catéchisme. Ces deux évolutions importantes ont influencée aussi bien le domaine pédagogique que celui du contenu même de cette catéchèse. La pédagogie de l'enseignement, qui considérait le " catéchisé » comme une " tabula rasa » a été remplacée par la pédagogie de l'apprentissage : considérer désormais le " catéchiste » comme protagoniste de l'acte catéchétique. Le contenu des rencontres, auparavant focalisé sur la doctrine, a cédé la place à la réalité historique du catéchiste. Plus que l'apprentissage de contenus, l'accent a été porté sur la lecture de la vie dans la perspective de la foi, en assumant ses défis et ses tensions, pour que cette vie soit transformée par la force du Dieu libérateur.

Mots-clés: Medellín. Catéchèse. Bible.

\footnotetext{
* Doutora e mestra em Teologia pela Faculdade Jesuíta de Filosofia e Teologia (FAJE). Atualmente, é professora da Pontifícia Universidade Católica de Minas Gerais (PUC Minas) e do Instituto Santo Tomás de Aquino (ISTA). E-mail: carmosolange@gmail.com

** Mestre em Teologia pela Faculdade Jesuíta de Filosofia e Teologia (FAJE) e graduado em Filosofia pelo Instituto Santo Tomás de Aquino (ISTA). E-mail: jfjunior_10@yahoo.com.br
} 


\section{INTRODUÇÃO}

A Conferência Episcopal de Medellín é um daqueles eventos que não envelhece. Sua mensagem ecoa entre nós depois de 50 anos, interpelando-nos a seguir em frente na construção do Reino sonhado por Jesus: um mundo mais fraterno e igualitário, no qual os empobrecidos são protegidos e amparados pela força da fé. Depois de Medellín, nunca mais a Igreja da América Latina foi a mesma. Uma identidade eclesial fortemente marcada pela leitura popular da bíblia se desenvolveu, deixando marcas importantes na catequese.

\section{O GIRO HERMENÊUTICO DE MEDELLÍN}

Ainda nem bem se havia recuperado da perplexidade causada pelo Concílio Vaticano II, especialmente pelas provocações das Constituições Dei Verbum, Lumen Gentium e Gaudium et Spes, quando o episcopado da América Latina se reuniu na cidade de Medellín, na Colômbia, em sua II Conferência Geral, em agosto de 1968. E não poderia ser de outro modo. Pois, se é verdade que o Vaticano II reconciliara a Igreja com a modernidade, é também verdade que o homem moderno latinoamericano (vivendo na periferia do mundo, sob regimes ditatoriais, em sua maioria abaixo da linha da pobreza e com sua herança cultural dos povos ancestrais) se distinguia enormemente daquele interlocutor imediato dos padres conciliares. De modo que a Conferência de Medellín tornou-se para a América Latina aquilo que o Vaticano II passou a representar para a Igreja Universal.

O Concílio não publicou um documento específico sobre a catequese, mas, na Constituição Dogmática Dei Verbum e em seu giro hermenêutico da revelação, a catequese encontrou seu novo ponto de partida. Dei Filius, do Vaticano I, ainda se inscrevia num paradigma teocêntrico, em que Deus revela "princípios imutáveis" sobre sua vontade, comunicando-os aos seres humanos por meio da doutrina elaborada pelo magistério eclesiástico (“depósito da fé”). Dei Verbum repropõe a revelação em termos cristocêntricos: Deus se revela a si mesmo, não num texto, mas na narrativa existencial de Jesus de Nazaré, em sua encarnação, em sua ação no mundo, em seu projeto do Reino, em sua entrega amorosa na cruz e em sua ressurreição. Em Jesus encontram-se, simultaneamente, a história de Deus no 
mundo e do ser humano em Deus. Portanto, ao contrário do que propunha o esquema dualista pré-conciliar, Dei Verbum estabelece um princípio de unidade: não só as fontes da revelação se constituem como uma só expressão de Deus, mas também as histórias de Deus e do mundo são, no fundo, uma única história, a história da salvação, em que Deus se diz na história humana.

Esse princípio de unidade da história fundamenta a reflexão de Gaudium et Spes, expresso já em seu solene verso de abertura:

As alegrias e as esperanças, as tristezas e as angústias dos homens de hoje, sobretudo dos pobres e de todos aqueles que sofrem, são também as alegrias e as esperanças, as tristezas e as angústias dos discípulos de Cristo. Não se encontra nada verdadeiramente humano que não lhes ressoe no seu coração"1.

E por que as tramas da história humana interessam aos discípulos de Cristo? Porque foi exatamente em meio a essas tramas que Deus realizou, na vida humana de seu Filho, da encarnação à cruz, a revelação de seu amor. Em Jesus e na palavra definitiva de vida pronunciada sobre ele pelo Pai, finalmente compreendemos que a tessitura da história humana, com seus avessos e direitos, interessa, em última instância, a Deus mesmo.

A reviravolta hermenêutica da revelação em Dei Verbum e seu princípio de unidade da história desenvolvido em Gaudium et Spes formam, portanto, o horizonte teológico de Medellín. Para captar a revelação de Deus, narrada em termos históricos, a Igreja deve olhar não para um depósito doutrinal, mas para a dinamicidade da história. Pois a revelação, que não expressa um conteúdo mas a presença de Deus, possui a mesma organicidade da história humana e, consequentemente, nela o mistério de Deus se diz do modo vivo e disponível ao olhar de todo ser humano. Essa convicção aparece mesmo nos textos preliminares do documento de Medellín: "Não temos soluções técnicas, nem remédios infalíveis (para os problemas da América Latina). Queremos sentir os problemas, perceber as exigências, compartilhar as angústias, descobrir os caminhos e colaborar nas soluções"2.

Ou seja, as intuições do Vaticano II foram apropriadas pela Igreja latinoamericana, em Medellín, de maneira tão fiel quanto original (como é próprio da Tradição). Essa originalidade - o princípio de unidade da história levado às últimas

1 Gaudium et Spes 1.

2 Medellín, Mensagem, p. 37 . 
consequências, tanto no magistério doutrinal quanto na ação pastoral, expresso na conhecida expressão "fé e vida" -, que lançou luzes sobre a realidade própria do continente, terminou por se constituir como o traço teológico que marcaria de

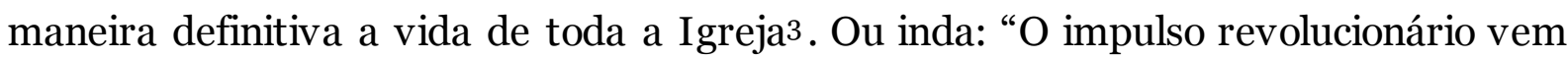
de Medellín: o Terceiro Mundo, hoje, lança seus refletores sobre o Primeiro que o gerou" 4 .

\section{A LEITURA POPULAR dA Bíblia}

Ao afirmar o princípio "fé e vida”, a Igreja latino-americana, de alguma forma, retira da instituição eclesiástica o protagonismo da fé, para recolocá-lo na vida do povo, lá onde o Deus da história se revela. E, interpelada pelas realidades populares, culturais, políticas e econômicas, essa recolocação do protagonismo da fé nas mãos do povo resulta necessariamente, como consequência do evangelho de Jesus, numa clara "opção pelos pobres”, apesar de essa expressão ainda não aparecer no texto de Medellín.

A ordem específica do Senhor de evangelizar os pobres deve levar-nos a uma distribuição tal dos esforços e do pessoal apostólico que se dê preferência efetiva aos setores mais pobres, necessitados e segregados por um motivo ou outro, estimulando e acelerando as iniciativas e estudos que se vêm realizando neste sentido5.

Nessa opção pelos pobres, o relato do êxodo e daquela luta dos pequenos diante do Faraó se torna paradigmático e performativo: "Eu vi, eu vi a miséria do meu povo que está no Egito. Ouvi seu clamor por causa dos seus opressores, pois eu conheço as suas angústias. Por isso desci a fim de libertá-lo das mãos dos egípcios” (Ex 3,7-8a). Como aos antigos, na América Latina, Deus se revela aos pequenos e oferece ao povo sua presença libertadora. Essa ótica se aplica ao evangelho de Jesus, ao Cristo Libertador que não só vence o pecado e a morte, mas que conclama a vencer as estruturas sociais de pecado e de morte. Assim, os pobres - escolhidos na opção da

\footnotetext{
3 Christian DUQUOC, “Une unique histoire”, Receherche de Science Religieuse 2, 1986, p. 201-215. 4 Silvio RIVAS, Una tipologia del catechista per la catechesi del nostro tempo, LDC, Turim, 1977, p. 33. Apud Ralfy, MENDES OLIVEIRA, "O movimento catequético brasileiro saindo das sombras", en Mauro PASSOS (org.), Uma história no plural, Vozes, Petrópolis, 1999, p. 61-114. 5 Medellín, Pobreza, 9.
} 
Igreja -, inspirados pela militância do Êxodo ou pela resistência dos primeiros cristãos oprimidos pelos judeus e pelos romanos, se organizam em pequenos grupos de vivência da fé e de partilha da vida. Na América Latina, essa organização eclesial se denominou Comunidades Eclesiais de Base (CEBs). Nesse nicho eclesial, o povo faz memória de sua vida à luz da Palavra de Deus, buscando em Jesus Cristo Libertador a força para sua caminhada, tal como no salmo: "Tua Palavra é lâmpada para os meus pés e luz para meu caminho" (Sl 119,105). Sob a ótica da fé cristã, as comunidades reveem sua vida, sua caminhada, acreditando que, como afirma a Gaudium et Spes, "Cristo manifesta plenamente o homem ao próprio homem"6.

Um caldo cultural como esse não poderia inspirar uma leitura da bíblia afeita às minúcias da crítica histórica, tampouco às alegorias espirituais da patrística, menos ainda à defesa apologética da doutrina instrumentalizada pela instituição. Surge aqui uma teologia bíblica feita não para os pobres, mas pelos pobres, que encontram em sua vida e em suas lutas a presença de Deus que convida à libertação. Entre a bíblia e a vida forma-se um "círculo hermenêutico": a vida suscita aquelas questões vitais (não meras querelas escolares) a serem respondidas pelo texto sagrado; os relatos bíblicos iluminam a vida com esperança e dão critérios para a ação a ser empreendida em nome da fé. Nessa leitura, ganham importância máxima os detalhes do dia-a-dia, os encantos da natureza, o trabalho dos homens e das mulheres, os encontros festivos, a cultura dos povos etc. A linguagem racional para dizer a fé dá lugar à linguagem simbólica, pois o povo latino-americano

prefiere flores a palabras, música a fríos conceptos, cálidos abrazos a discursos, agua bendita a largas homilías, parábolas, cuentos y mitos a ideología racional y lógica greco-latina. De aquí nace también una teología diversa de la occidental, con una sabiduría propia y peculiar, más cercana al mundo semítico y hebreo que al occidental moderno ${ }^{7}$.

Esse método popular de leitura bíblica, rapidamente, cunhou um caminho epistemológico da fé. Já em Medellín, a redação de certos capítulos obedece a esta metodologia: lançar um olhar sobre a realidade; iluminá-lo a partir da fé, sobretudo das Sagradas Escrituras; e agir concretamente em nome dessa fé. Mas foi em Puebla,

\footnotetext{
6 Gaudium et Spes 22.

7 CODINA, Victor. El camino teológico de la CLAR, p. 74. Conferencia Ecuatoriana de Religiosos/as. Disponível em: <http://www.vidadelacer.org/images/documentos/codina.pdf >. Acesso em: 13 nov. 2017 .
} 
na terceira conferência geral do episcopado, em 1979, que o "ver-julgar-agir" se consagrou como o método por excelência da teologia e da pastoral latino-americanas. Depois disso, o método reaparece aplicado em todos os âmbitos: planos pastorais, projetos de evangelização, roteiros de encontros populares etc. Bons exemplos desse método são o projeto "Palavra-Vida", da Conferência Latino-americana dos Religiosos (CLAR), e o trabalho pioneiro do frei Carlos Mesters no Brasil, com os círculos bíblicos.

\section{IMPACTO DE MEDELLÍN NA CATEQUESE DA AMÉRICA LATINA}

A assimilação desse método popular de leitura da bíblia teve consequências nos caminhos da catequese na América Latina. E essas mudanças se devem ao lugar que a Escritura Sagrada assumiu no encontro catequético. Os antigos manuais e os catecismos de perguntas e repostas mostraram sua caducidade frente à liberdade e à lucidez dos textos bíblicos, lidos à luz da vida cotidiana dos pobres. Tornou-se inconcebível desenvolver um encontro catequético sem a iluminação de um texto da bíblia, sem que ele fosse discutido e partilhado por todos os presentes. Não que a bíblia tenha se tornado um novo manual ou que o encontro catequético tenha se tornado uma aula de bíblia. Mas tal foi a identificação da catequese com a leitura popular da bíblia, que catequistas e catequizandos viam sua história refletida em cada relato, em cada narrativa emergida das Escrituras. É o caso da Catequese Renovada, no Brasil, que deu centralidade à bíblia. Nesse tipo de catequese, a bíblia não se tornou foco de estudo mas espelho da vida, ou melhor, o exercício de um olhar capaz de captar a vida em sua profundidade. Entendeu-se que

As situações históricas e as aspirações autenticamente humanas constituem parte indispensável do conteúdo da catequese e devem ser interpretadas seriamente, dentro de seu contexto social, à luz das experiências vividas pelo Povo de Israel, de Cristo, e da comunidade eclesial, na qual o Espírito de Cristo ressuscitado vive e opera continuamente ${ }^{8}$.

8 Medellín, Catequese, n. 6. 
Assim, a partir da leitura bíblica popular, dois impactos muito profundos ficaram sacramentados na catequese latino-americana: o primeiro, de natureza pedagógica; o segundo, de conteúdo.

No campo pedagógico, a catequese tradicional, herdeira dos catecismos tridentinos, se desenvolvia nos moldes da escolástica. Os catecismos eram compreendidos como pequenas sumas teológicas, de cujo alcance nada significativo poderia escapar. A preocupação central dessa pedagogia era a exatidão na transmissão dos conteúdos doutrinais, a serem assimilados de forma preponderantemente teórica. O catequista, tal como um professor, possuía as credenciais da instituição para o ensino da doutrina, donde decorre o peso sobre a sua vida moral como critério de legitimidade. Por outro lado, como mero expositor da doutrina, o catequista não exigia da Igreja institucional um processo de formação muito elaborado, já que bastava repetir à exaustão as perguntas e respostas dos catecismos. Nessa pedagogia do ensino, o catequizando era compreendido como uma tábula rasa, sobre o qual se deveriam depositar categorias nocionais e abstratas da fé cristã.

Com a centralidade da Escritura, os encontros catequéticos assistem ao nascimento de uma outra pedagogia. A Palavra proclamada precisava ser partilhada e atualizada, ou seja, precisava ser tornada carne na vida dos catequizandos, por meio de uma profunda identificação do texto com a vida. Não se trata mais de assimilar conteúdos da fé, sabendo de cor conceitos e orações, regras morais ou mandamentos, mas de saber olhar a vida - a própria narrativa existencial e a realidade social - a partir da fé. O catequizando ganha voz, como interlocutor do texto sagrado. E o mesmo texto, diante de interlocutores distintos, se torna capaz de responder de forma diferente aos anseios de cada um. Mulheres, lavradores, operários ou estudantes passam a encontrar no texto não uma fórmula a ser decorada, mas uma chave hermenêutica da própria vida, ou seja, descobrem não uma revelação imutável de Deus, mas a presença do Deus que se revela em sua própria história. O catequizando deixa de ser um parceiro da Igreja institucional, continuador da transmissão da doutrina, para se tornar um agente sócio-transformador, empenhado na construção do Reino de Deus. Deseja-se que, para além dos muros da instituição, seu lugar de atuação seja o mundo. Essa pedagogia da aprendizagem permitiu a entrada de novos elementos didáticos na catequese: cantos populares, orações e ritos da religiosidade 
popular, expressões religiosas próprias de grupos culturais específicos ou dos povos ancestrais. Tudo se tornou sacramento da presença de Deus, da trouxa de roupas da lavadeira à enxada do agricultor, do tambor dos quilombolas às flautas indígenas, dos grãos colhidos com suor nas roças às manufaturas e às lutas dos operários nas cidades. Tal era a amplidão sacramental que o reducionismo da pedagogia do ensino dos velhos catecismos se mostrava ineficaz.

Quanto ao conteúdo, já fica fácil inferir. A catequese tradicional partia da ideia do Deus eterno, todo-poderoso e imutável, que dispunha da vida humana a partir de sua vontade e cujos desígnios eram expressos na doutrina e na moral. Tão abstrata quanto essa ideia de Deus era a compreensão da salvação e suas consequências na vida pós-morte. Os catecismos insistiam na temática da salvação do pecado, da justiça de Deus e das penas reservadas ao pecador. Vivia-se em função do culto e das boas obras que fizessem merecem a salvação. Não havia espaço para os problemas humanos, para as injustiças sociais, para as incoerências do sistema econômico, para os diretos humanos etc. "Salvar a alma" era a tônica de todos os conteúdos da catequese.

A virada hermenêutica de Medellín, no horizonte aberto por Dei Verbum e Gaudium et Spes, não só lançou novas luzes sobre a vida presente e seus desafios, como a elegeu como lugar da revelação de Deus. É de Medellín, por exemplo, a afirmação de que a Igreja, serva da humanidade, deve se preocupar com a educação das pessoas, não só catequética, mas integral9. Ou ainda, que "se deve manifestar sempre a unidade profunda que existe entre o plano salvífico de Deus, realizado em Cristo, e as aspirações do homem; entre a história da salvação e a história humana; entre a Igreja, povo de Deus, e as comunidades temporais; entre a ação reveladora de Deus e a experiência humana; entre os dons e carismas sobrenaturais e os valores humanos"10. Se o palco da vida e a narrativa da história são o lugar excelente da revelação de Deus, não há nenhuma experiência verdadeiramente humana que não interesse à fé cristã e, por consequência, à catequese. Por isso, “a catequese não pode ignorar em sua renovação as mudanças econômicas, demográficas, sociais e culturais sofridas na América Latina"11. Ou ainda, de modo mais claro: “as situações históricas

\footnotetext{
9 Medellín, Educação, 17 .

10 Medellín, Catequese, 4.

${ }^{11}$ Medellín, Catequese, n. 5 .
} 
e as aspirações autenticamente humanas constituem parte indispensável do conteúdo da catequese"12.

Em suma: se o conteúdo da catequese é a vida humana e a trama de sua história, somente uma pedagogia ampla se mostra capaz de comunicá-lo; a essa pedagogia tão abrangente, somente um conteúdo tão profundo pode corresponder.

\section{CONSIDERAÇÕES FINAIS}

Por um lado, é notório que a catequese latino-americana nunca mais foi a mesma depois de Medellín. Sua virada de conteúdo e de método são ganhos permanentes na história da catequese, não sendo possível conceber a ação catequética de volta aos catecismos e à transmissão formal da doutrina, apesar das atuais tendências neoconservadoras.

Por outro lado, parece legítimo admitir que as circunstâncias históricas que motivaram o giro catequético impulsionado por Medellín não são mais as mesmas dos anos 1960. Há novos contextos culturais, novos sujeitos eclesiais e novas realidades de Igreja que exigem um novo paradigma catequético, sem abandonar os ganhos que a catequese libertadora, filha de Medellín, nos angariou. Desafios como a construção da interioridade, o anúncio do evento-Cristo - em vistas de superar o déficit de iniciação à fé -, a elaboração de novos vínculos de pertença eclesial e a redescoberta da iniciação como pedagogia original da fé não podem ser ignorados por catequetas e catequistas que pretendam o anúncio da fé nos tempos atuais.

\section{REFERÊNCIAS}

BÍBLIA DE JERUSALÉM. Nova edição, revista e ampliada. São Paulo: Paulus, 2004.

MENDES OLIVEIRA, Ralfy. O movimento catequético brasileiro saindo das sombras. In: PASSOS, Mauro (org.). Uma história no plural. Petrópolis: Vozes, 1999. p. 61114 .

DUQUOC, Christian. Une unique histoire: receherche de Science Religieuse 2, 1986, p. 201-215.

\footnotetext{
12 Medellín, Catequese, n. 6.
} 
CONFERÊNCIA EPISCOPAL LATINO-AMERICANA: conclusões de Medellín, 7 ed., Petrópolis: Vozes, 1980.

COMPENDIO DO VATICANO II : constituições, decretos, declarações, 18ed., Petrópolis: Vozes, 1986.

RIVAS, Silvio. Una tipologia del catechista per la catechesi del nostro tempo. Turim: LDC, 1977.p. 33.

CODINA, Victor. El camino teológico de la CLAR, p. 74. Conferencia Ecuatoriana de Religiosos/as. Disponível em:

<http://www.vidadelacer.org/images/documentos/codina.pdf>. Acesso em: 13 nov. 2017.

Recebido em: 15.03 .2018 Aprovado em: 08.09.2018 